\title{
Bilateral Mastodynia: An Unusual Presentation of Calciphylaxis
}

\section{Mastodinia Bilateral: Uma Apresentação Invulgar de Calcifilaxia}

Margarida da Silva CUNHA $\rrbracket^{1}$, Xavier de SOUSA ${ }^{1,2}$, Jorge SIMÕES ${ }^{1}$

Acta Med Port 2019 Jan;32(1):86-86 - https://doi.org/10.20344/amp.10495

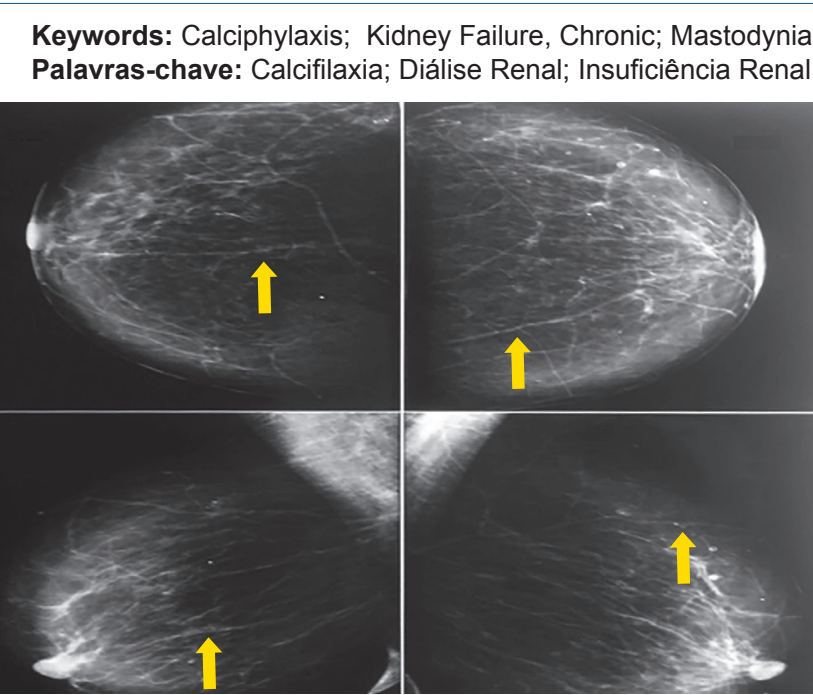

Figure 1 - Bilateral mammography showing stromal and vascular calcifications (arrows). No masses or microcalcifications were noted

A 62-year-old female with end-stage renal disease (ESRD) on hemodialysis and atrial fibrillation under warfarin presented with strong bilateral mastodynia without palpable masses. Her mammography showed stromal and vascular calcifications (Fig. 1). Within three months, multiple painful subcutaneous nodules appeared sequentially in the breasts (Fig. 2) and abdomen whose histological results were inconclusive. An infected ulcer at the abdominal biopsy site led to the patient's hospitalization. Investigation revealed elevated phosphorus $(4.9 \mathrm{mg} / \mathrm{dL})$ and PTH (2284 $\mathrm{pg} / \mathrm{mL})$. Another skin biopsy confirmed calciphylaxis.

\footnotetext{
ACKNOWLEDGEMENTS: Authors are thankful to M Gonçalves, (Pathology Department, Setúbal Medical Centre).

OBSERVATIONS: The described case was presented, partially and before it was concluded, at the XVI Jornadas de Senologia, which took place at Braga on October 15, 2016

PROTECTION OF HUMANS AND ANIMALS: The authors declare that the procedures were followed according to the regulations established by the Clinical Research and Ethics Committee and to the Helsink Declaration of the World Medical Association.
}

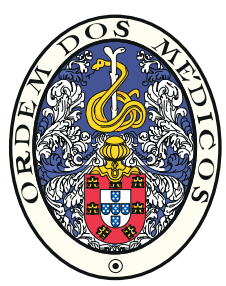

\section{(1)}

